\title{
Successful non-exposed endoscopic wall-inversion surgery for gastric stromal tumor and gastric ESD for dysplastic lesion during a single procedure
}

For gastrointestinal stromal tumors, the risk of lymph node metastasis is considered negligible and partial gastric resection without lymphadenectomy is accepted [1]. However, conventional gastric wall resections are associated with intentional perforation with a risk of bacterial contamination and tumor cell seeding into the peritoneum. To avoid this dissemination, non-exposed endoscopic wallinversion surgery has been developed [2, 3] but never reproduced outside Japan [4].

We proposed such a procedure to a 57-year-old man for a 22-mm submucosal tumor of the fundus on the anterior wall close to the lesser curvature. Unfortunately, while surgeons were inserting the laparoscope, a small sessile gastric lesion with a depressed area on the top and an irregular mucosal pattern was detected just below the cardia during the endoscopy. To avoid cancelling the procedure, we performed an en bloc en-

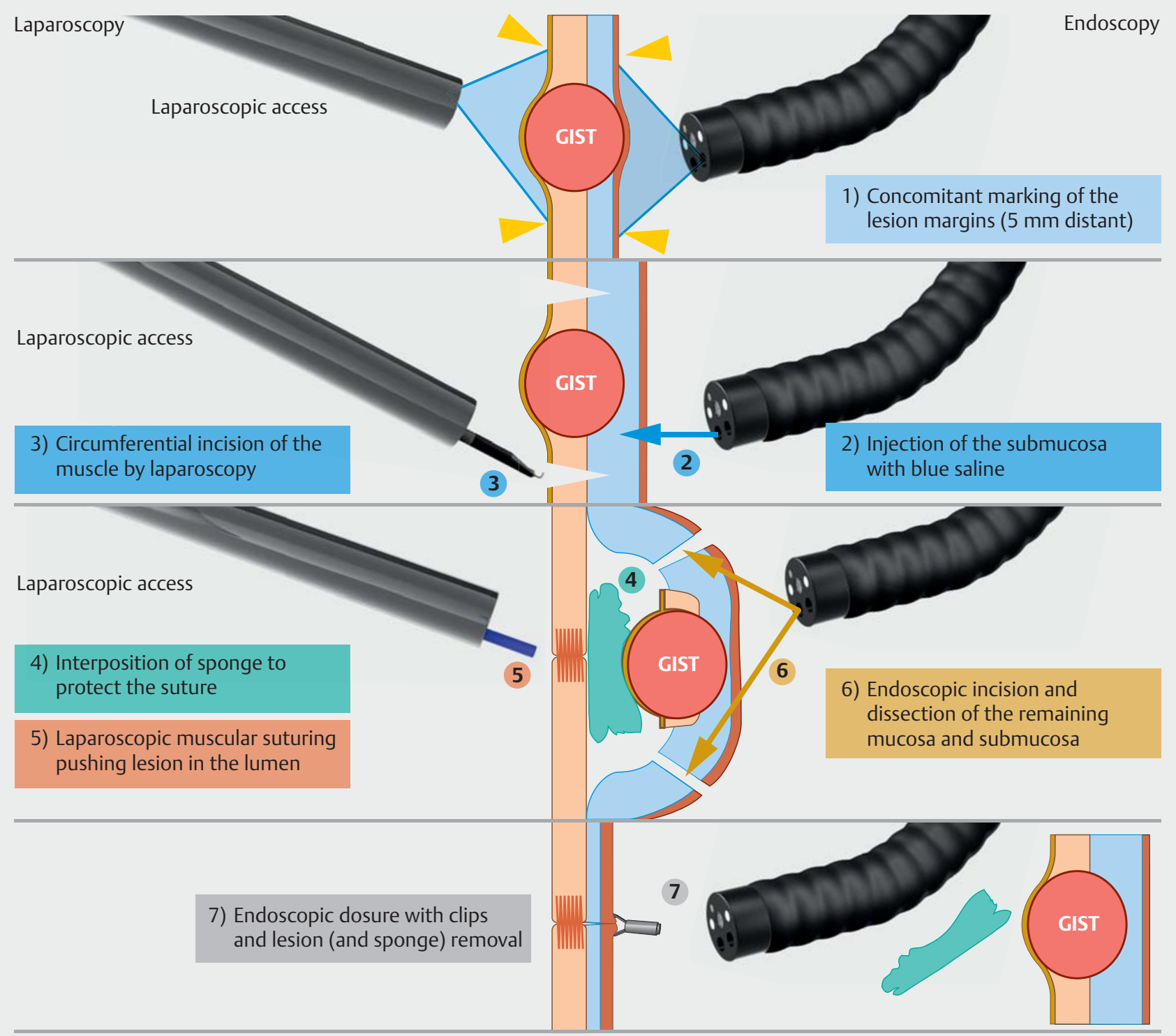

Fig. 1 Schematic description of the procedure. 

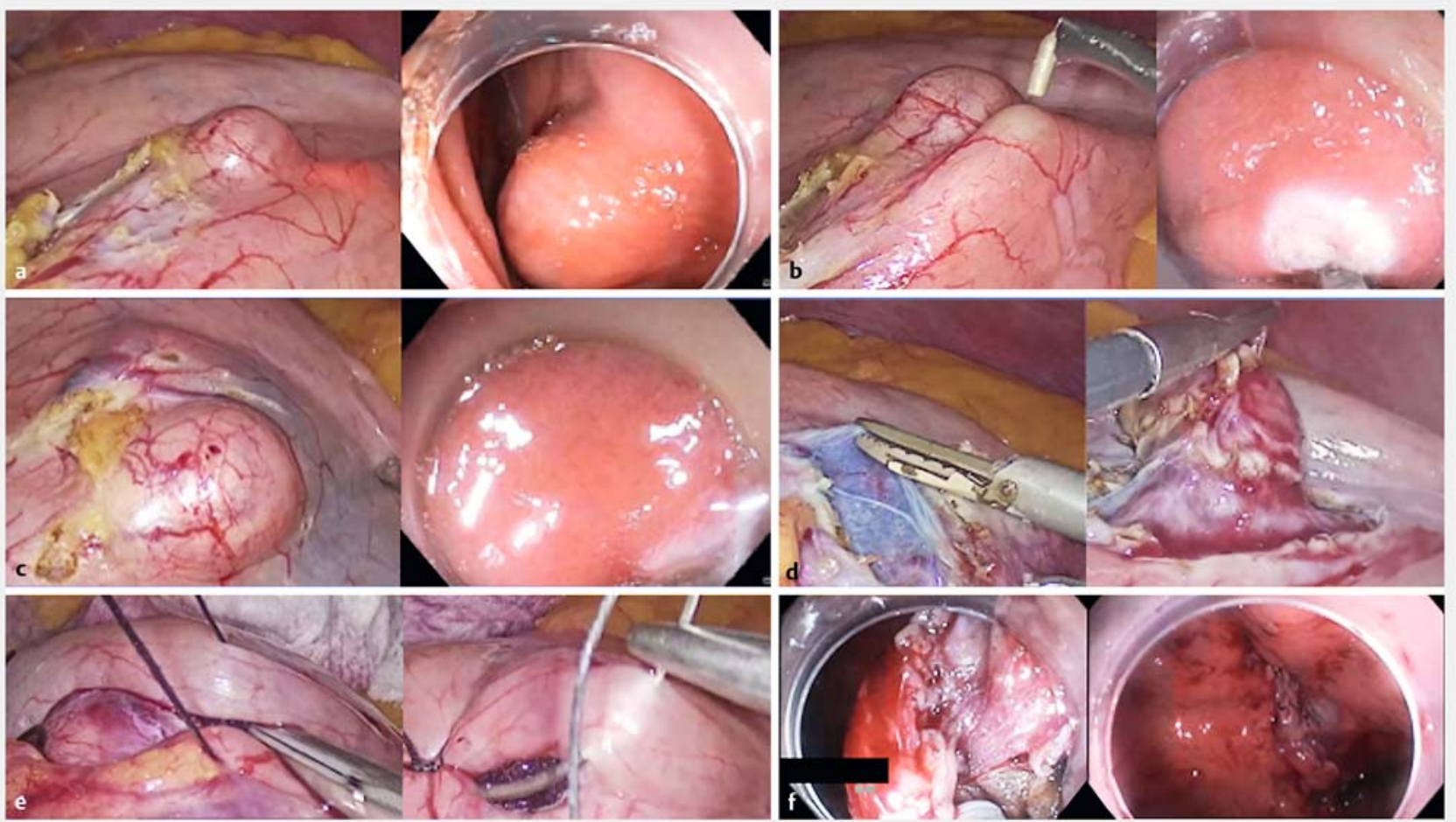

Fig. 2 Description of the procedure. a Laparoscopic and endoscopic aspects of the stromal tumor. b Concomitant marking on the two sides. c Submucosal injection with blue saline solution. $\mathbf{d}$ Seromuscular incision up to the blue submucosal cushion. e Suture on a sponge to push the lesion into the stomach. $\mathbf{f}$ End of procedure with endoscopic mucosal incision and submucosal dissection and then clip closure.

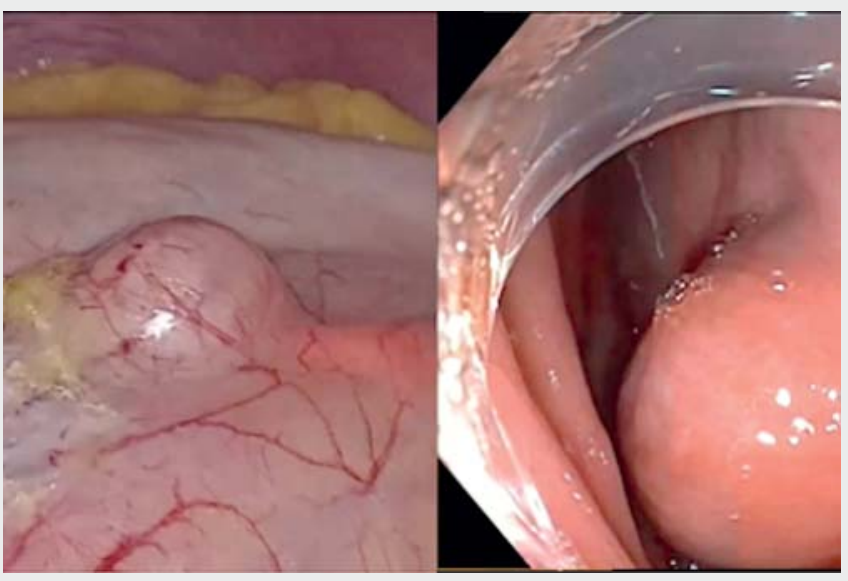

Video 1 Successful non-exposed endoscopic wall-inversion surgery for gastric stromal tumors and gastric endoscopic submucosal dissection for dysplastic lesion during a single procedure.

doscopic submucosal dissection (ESD) procedure of the lesion ( $\vee$ Video 1 ), and then sent the specimen for extemporaneous pathology examination, which confirmed the lack of invasive adenocarcinoma. Non-exposed endoscopic wall-inversion surgery was pursued $[2,3]$ with circumferential marking ( $\mathbf{F i g . 1 \text { , }}$

- Fig.2) and submucosal injection with blue saline; surgeons performed the muscular and submucosal incision laparoscopically. Then, two small pieces of sponge were placed against the tumor in order to cover the area with a suture of the gastric wall, pushing the lesion towards the gastric lumen. Once that step was complete without any gastric leakage, the mucosa and remaining submucosa were cut circumferentially by ESD using a DualKnife (Olympus, Tokyo, Japan). The full-thickness specimen was removed endoscopically. Patient resumed eating on day three after the lack of leakage was confirmed (gastric opacification) and was discharged on day five.

To summarize, non-exposed endoscopic wall-inversion surgery is an exciting technique combining endoscopy and laparoscopic surgery to remove gastric tumors without any periprocedural communication of the gastric lumen with the peritoneum, thus reducing the risk of cell seeding. This technique is reproducible outside Japan and seems minimally invasive.

Endoscopy_UCTN_Code_TTT_1AO_2AG 


\section{Competing interests}

The authors declare that they have no conflict of interest.

The authors

Arnaud Pasquer ${ }^{1}{ }^{\oplus}$, Gilles Poncet ${ }^{1}$, Florian Rostain ${ }^{2}$, Jérôme Rivory ${ }^{2}$, Valérie Hervieu ${ }^{3}$, Julie Périnel ${ }^{1}$, Mathieu Pioche ${ }^{2}$

1 Digestive Surgery Unit, Edouard Herriot Hospital, Hospices Civils de Lyon, Lyon, France

2 Endoscopy and Gastroenterology Unit, Edouard Herriot Hospital, Hospices Civils de Lyon, Lyon, France

3 Pathology Division, Hospices Civils de Lyon, Lyon, France

\section{Mathieu Pioche, MD}

Endoscopy Unit - Digestive Disease

Department, Pavillon L - Edouard Herriot

Hospital, 69437 Lyon Cedex , France

mathieu.pioche@chu-lyon.fr

\section{References}

[1] Nishida T, Hirota S, Yanagisawa A et al. Clinical practice guidelines for gastrointestinal stromal tumor (GIST) in Japan: English version. Int J Clin Oncol 2008; 13: 416-430

[2] Goto O, Takeuchi H, Kawakubo H et al. First case of non-exposed endoscopic wall-inversion surgery with sentinel node basin dissection for early gastric cancer. Gastric Cancer 2015: 18: 434-439

[3] Aoyama J, Goto O, Kawakubo H et al. Clinica outcomes of non-exposed endoscopic wallinversion surgery for gastric submucosal tumors: long-term follow-up and functional results. Gastric Cancer 2019. doi:10.1007| s10120-019-00985-1

[4] Fujishiro M, Furukawa K, Yamamura T et al. Nonexposed wall-inversion surgery as a novel local resection method for neoplasms in the gastrointestinal tract. Nagoya J Med Sci 2020; 82: 175-182
Bibliography

Endoscopy 2021; 53: E452-E454

DOI $10.1055 / a-1324-2249$

ISSN 0013-726X

published online 4.2.2021

(c) 2021. Thieme. All rights reserved.

Georg Thieme Verlag KG, Rüdigerstraße 14,

70469 Stuttgart, Germany

\section{ENDOSCOPY E-VIDEOS}

https:/|eref.thieme.de/e-videos

口回 Endoscopy E-Videos is a free access online section, reporting 回证: on interesting cases and new

techniques in gastroenterological endoscopy. All papers include a high quality video and all contributions are freely accessible online.

This section has its own submission website at https://mc.manuscriptcentral.com/e-videos 